\title{
Epithelial-myoepithelial carcinoma: a population-based survival analysis
}

\author{
Mitchell R. Gore(D)
}

\begin{abstract}
Background: Epithelial-myoepithelial carcinoma is an uncommon malignant neoplasm seen most frequently in the salivary glands, representing approximately 1 to $2 \%$ of salivary gland tumors. Less than 600 cases have been reported in the literature since its initial description in 1972. The aim of this study was to examine demographic, site, stage, and survival factors in patients with epithelial-myoepithelial carcinoma.

Methods: The 1973-2014 SEER (Surveillance, Epidemiology, and End Results) cancer database was queried for patients treated for epithelial-myoepithelial carcinoma. The data was analyzed for patient T (tumor), N (nodal), and M (metastasis) stage, tumor site, and demographic characteristics. The Kaplan-Meier model was used to estimate actuarial survival.

Results: A total of 468 patients were identified. White patients represented $78.0 \%$ of the total. There were 291 female patients and 177 male patients. Overall 5-, 10-, and 20-year survival was $72.7 \%, 59.5 \%$, and 38.3\%, respectively. Mean survival time was 165.5 months. Parotid gland was the most common site with $57.7 \%$ of patients, with submandibular gland representing $9.8 \%$ of patients. Distant metastasis (M) status was unknown in 33.3\%, with 2.6\% being M1, 3.0\% being $\mathrm{MX}$, and $61.1 \% \mathrm{MO}$. Nodal metastasis (N) status was unknown in 33.3\%, while 4.4\% were $\mathrm{N}+, 4.7 \%$ were $\mathrm{NX}$, and $57.5 \%$ were N0. 88.2\% of patients had surgery as part or all of the treatment regimen. Univariate Kaplan-Meier analysis showed that AJCC overall stage, primary tumor (T) stage, nodal (N) stage, presence of distant metastasis (M1), age at diagnosis, race, and non-surgical treatment significantly affected survival. On multivariate analysis age, race, AJCC stage, T, N, M stage, and treatment type were significant.
\end{abstract}

Conclusions: Epithelial-myoepithelial carcinoma is a malignant, histologically biphasic neoplasm most frequently seen in the parotid gland. The nodal and distant metastasis rates are low. Age at diagnosis, race, AJCC stage, T, N, M stage, and treatment type all significantly affected survival.

Keywords: Epithelial-myoepithelial carcinoma, Salivary gland, SEER, Surveillance epidemiology and end results, Population based

\section{Background}

Epithelial-myoepithelial carcinoma is a relatively uncommon malignant neoplasm. It comprises approximately 1 to $2 \%$ of salivary gland neoplasms [1-3]. The histology of the tumor shows a biphasic pattern with clear myoepithelial cells encasing ducts with an epithelial lining. The tumor is typically regarded as a low-grade malignancy due to its low rate of nodal and distant metastasis [2]. In 2015 Vazquez et al. [2] examined the 1973-2010 SEER (Surveillance, Epidemiology, and End Results) database for patients with epithelial-myoepithelial carcinoma

Correspondence: mgoremdphd@gmail.com

Department of Otolaryngology, SUNY Upstate Medical University, Physicians Office Building North, Suite 4P, 4900 Broad Road, Syracuse, NY 13215, USA of the salivary glands. They noted 246 total cases with only $4.5 \%$ having distant metastases (M1). They noted an overall disease-specific survival (DSS) at 60 and 120 months of $91.3 \%$ and $90.2 \%$, respectively. They noted that the majority of patients (95.7\%) had surgery alone or in combination with another treatment such as radiation. The mean age was 63.8 years.

The goal of the present study was to update the SEER analysis for the 1973-2014 database, and to examine the factors influencing survival for patients with epithelial-myoepithelial carcinoma at all sites, including salivary primary sites. Demographic factors were examined and the Kaplan-Meier analysis was used to identify factors

(c) The Author(s). 2018 Open Access This article is distributed under the terms of the Creative Commons Attribution 4.0 International License (http://creativecommons.org/licenses/by/4.0/), which permits unrestricted use, distribution, and 
influencing survival in patients with epithelial-myoepithelial carcinoma.

\section{Methods}

The SEER (Surveillance Epidemiology and End Results) database contains patient data from 1973 to 2014. The database was queried for malignant neoplasm, epithelial-myoepithelial carcinoma, any site, any age, and was extracted using SEER*Stat version 8.3.4 (National Cancer Institute, Bethesda, Maryland) and exported into Microsoft Excel 2016 (Microsoft Corporation, Redmond, Washington) for analysis. XLstat Biomed (Addinsoft, New York City, NY/Paris, France) was used for Kaplan-Meier overall survival analysis and log-rank analysis. Statistical significance was set at 0.05. SEER data was analyzed for overall survival, patient age, sex, and race, and tumor $(\mathrm{T})$, nodal $(\mathrm{N})$, and distant metastasis $(\mathrm{M})$ stage, surgical treatment, and primary tumor site.

\section{Results}

A total of 468 patients were identified. Table 1 illustrates the demographic data for age, sex, and race of the cohort.

Table 1 Patient Demographics

\begin{tabular}{|c|c|c|}
\hline Total & 468 & $100 \%$ \\
\hline \multicolumn{3}{|l|}{ Age, years } \\
\hline $10-14$ years & 2 & $0.4 \%$ \\
\hline $15-19$ years & 2 & $0.4 \%$ \\
\hline 20-24 years & 2 & $0.4 \%$ \\
\hline $25-29$ years & 8 & $1.7 \%$ \\
\hline 30-34 years & 7 & $1.5 \%$ \\
\hline $35-39$ years & 10 & $2.1 \%$ \\
\hline 40-44 years & 15 & $3.2 \%$ \\
\hline $45-49$ years & 30 & $6.4 \%$ \\
\hline 50-54 years & 50 & $10.7 \%$ \\
\hline $55-59$ years & 55 & $11.8 \%$ \\
\hline 60-64 years & 44 & $9.4 \%$ \\
\hline $65-69$ years & 66 & $14.1 \%$ \\
\hline $70-74$ years & 60 & $12.8 \%$ \\
\hline $75-79$ years & 45 & $9.6 \%$ \\
\hline 80-84 years & 35 & $7.5 \%$ \\
\hline $85+$ years & 37 & $7.9 \%$ \\
\hline \multicolumn{3}{|l|}{ Sex } \\
\hline Female & 291 & $62.2 \%$ \\
\hline Male & 177 & $37.8 \%$ \\
\hline \multicolumn{3}{|l|}{ Race } \\
\hline White & 365 & $78.0 \%$ \\
\hline Black & 52 & $11.1 \%$ \\
\hline Other (American Indian/AK Native, Asian/Pacific Islander) & 46 & $9.8 \%$ \\
\hline
\end{tabular}

The majority of patients were $>50$ years of age, with 65-69 years of age being the largest age group. There was a female predominance, with a 1.6:1 Female:Male ratio. The majority of patients with epithelial-myoepithelial carcinoma were white $(78.0 \%)$, with black patients representing $11.1 \%$, patients identified as other representing $9.8 \%$, and race unknown in $1.1 \%$. Table 2 illustrates the Tumor $(\mathrm{T})$, Nodal $(\mathrm{N})$, and Metastasis $(\mathrm{M})$ characteristics of the cohort. The majority of the patients had T1 $(21.8 \%)$ or T2 (21.6\%) tumors. Of the patient cohort, $4.2 \%$ were $\mathrm{N}+$, $57.5 \%$ were N0, $4.7 \%$ were NX (nodal status could not be determined) and $33.3 \%$ had an unknown nodal status. With respect to distant metastases, $61.1 \%$ were M0, 2.6\% were M1, 5.2\% were MX (metastatic status could not be determined), and $33.3 \%$ had an unknown metastatic status. Table 3 shows the primary site location

Table 2 Patient tumor $(T)$, nodal $(N)$, and metastasis $(M)$ characteristics

\begin{tabular}{|c|c|c|}
\hline \multicolumn{3}{|l|}{$T$} \\
\hline T1 & 102 & $21.8 \%$ \\
\hline T1a & 3 & $0.6 \%$ \\
\hline T1c & 2 & $0.4 \%$ \\
\hline $\mathrm{T} 2$ & 101 & $21.6 \%$ \\
\hline T3 & 46 & $9.8 \%$ \\
\hline Т3а & 1 & $0.2 \%$ \\
\hline T3b & 1 & $0.2 \%$ \\
\hline T3c & 6 & $1.3 \%$ \\
\hline T3x & 1 & $0.2 \%$ \\
\hline T4 & 2 & $0.4 \%$ \\
\hline T4a & 13 & $2.8 \%$ \\
\hline T4b & 4 & $0.9 \%$ \\
\hline TX & 28 & $6.0 \%$ \\
\hline TXa & 2 & $0.4 \%$ \\
\hline unknown & 156 & $33.3 \%$ \\
\hline \multicolumn{3}{|l|}{ N } \\
\hline NO & 269 & $57.5 \%$ \\
\hline N1 & 16 & $3.4 \%$ \\
\hline $\mathrm{N} 1 \mathrm{x}$ & 2 & $0.4 \%$ \\
\hline N2 & 1 & $0.2 \%$ \\
\hline N2NOS & 1 & $0.2 \%$ \\
\hline N3 & 1 & $0.2 \%$ \\
\hline NX & 22 & $4.7 \%$ \\
\hline unknown & 156 & $33.3 \%$ \\
\hline \multicolumn{3}{|l|}{ M } \\
\hline MO & 286 & $61.1 \%$ \\
\hline M1 & 12 & $2.6 \%$ \\
\hline$M X$ & 14 & $5.2 \%$ \\
\hline unknown & 156 & $33.3 \%$ \\
\hline
\end{tabular}


Table 3 Patient primary site distribution

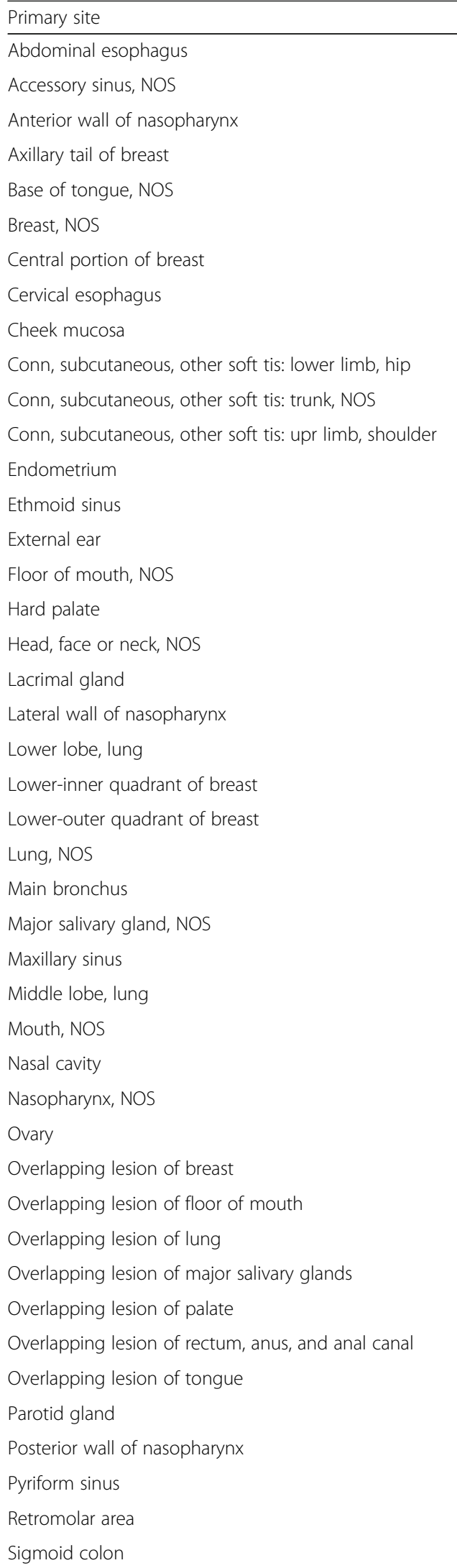

Table 3 Patient primary site distribution (Continued)

\begin{tabular}{lll}
\hline Primary site & & \\
\hline Skin of scalp and neck & 2 & $0.4 \%$ \\
Skin other/unspec parts of face & 5 & $0.2 \%$ \\
Soft palate, NOS & 1 & $0.1 \%$ \\
Sublingual gland & 46 & $9.8 \%$ \\
Submandibular gland & 1 & $0.2 \%$ \\
Tonsillar fossa & 3 & $0.6 \%$ \\
Trachea & 14 & $3.0 \%$ \\
Unknown primary site & 1 & $0.2 \%$ \\
Upper gum & 2 & $0.4 \%$ \\
Upper lobe, lung & 2 & $0.4 \%$ \\
Upper-inner quadrant of breast & 10 & $2.1 \%$ \\
Upper-outer quadrant of breast & & \\
\hline
\end{tabular}

of each patient. Parotid gland was the most common primary site, with $57.7 \%$, followed by submandibular gland with $9.8 \%$.

Figure 1 shows the Kaplan-Meier actuarial overall survival for the entire cohort. Overall survival at 5,10 , and 20 years was $72.7 \%, 59.5 \%$, and $38.3 \% \%$, respectively. Figure 2 illustrates the Kaplan-Meier actuarial overall survival by T stage. Survival was lower for T2, T3, and T4 patients than for T1 patients $(p<0.0001)$. Figure 3 shows the Kaplan-Meier actuarial overall survival by $\mathrm{N}$ stage. Survival was significantly lower for N1, N2, and N3 patients than for N0 patients $(p<0.0001)$. Figure 4 shows the Kaplan-Meier actuarial overall survival by $M$ stage. Survival for patients with no distant metastasis (M0) was significantly greater than M1 patients with distant metastasis present $(p=<0.0001)$. Figure 5 illustrates the Kaplan-Meier actuarial overall survival by primary site. There was no significant difference in survival for different primary sites $(p=0.6)$. Figure 6 illustrates the Kaplan-Meier actuarial overall survival by treatment regimen. Survival for patients on whom surgery was performed was significantly greater than patients for whom surgery was not recommended, patients for whom surgery was recommended but it was unknown whether the surgery was performed, and patients for whom surgery was recommended but not performed for an unknown reason $(p<0.0001)$. Figure 7 illustrates the Kaplan-Meier actuarial overall survival by overall AJCC (American Joint Committee on Cancer) stage. Survival decreased with increasing AJCC stage ( $>$ II $>$ III $>$ IV, $p<0.0001$ ). Figure 8 illustrates the Kaplan-Meier actuarial overall survival by sex. There was no significant difference in survival by sex $(p=0.2)$. Figure 9 illustrates the Kaplan-Meier overall survival by race. Survival was lower for black patients than for white or other (American Indian/AK (Alaska) Native, Asian/Pacific Islander), $p=0.01$ ). Figure 10 


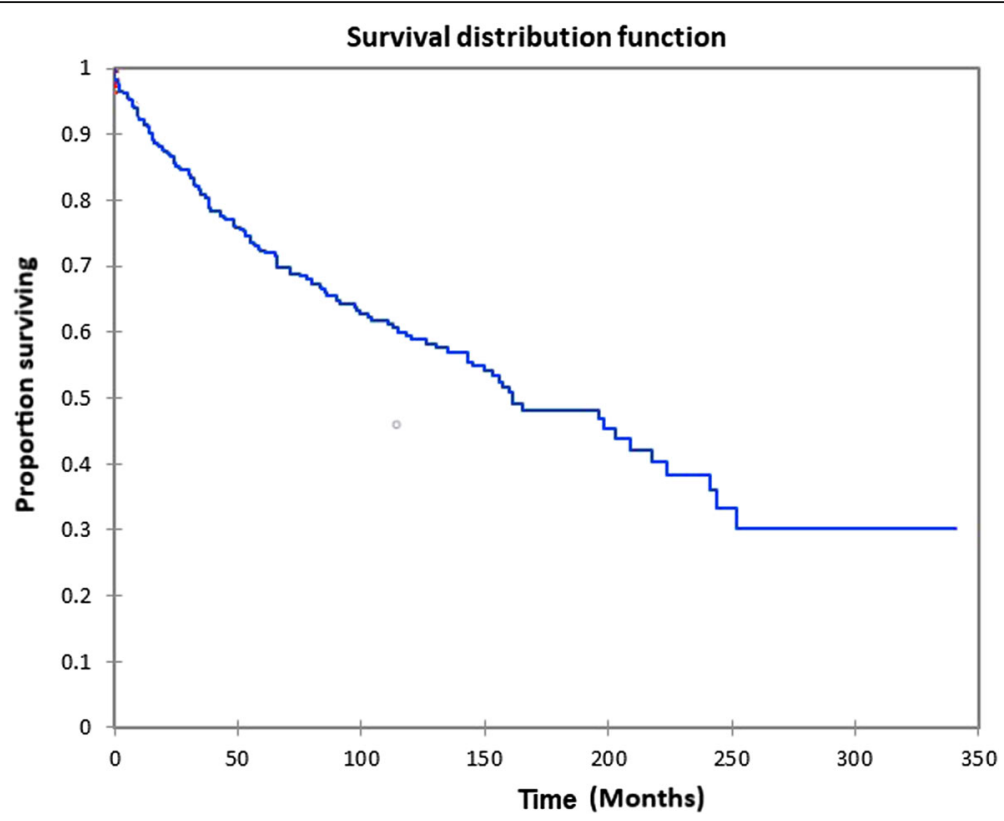

Fig. 1 Kaplan-Meier overall survival for all patients

illustrates the Kaplan-Meier overall survival by age at diagnosis. Survival was significantly lower for patients over age 80 at diagnosis $(p<0.0001)$. Multivariate logistic regression analysis was performed. This demonstrated that age $(p<0.0001)$, race $(p=0.02)$, AJCC stage $(p<0.0001)$,
$\mathrm{T}(p=0.006), \mathrm{N}(p<0.0001)$, and $\mathrm{M}(p=0.003)$ stage, and treatment type $(p<0.0001)$ were significantly associated with survival. Primary tumor site and patient sex were not significantly associated with survival on multivariate analysis.

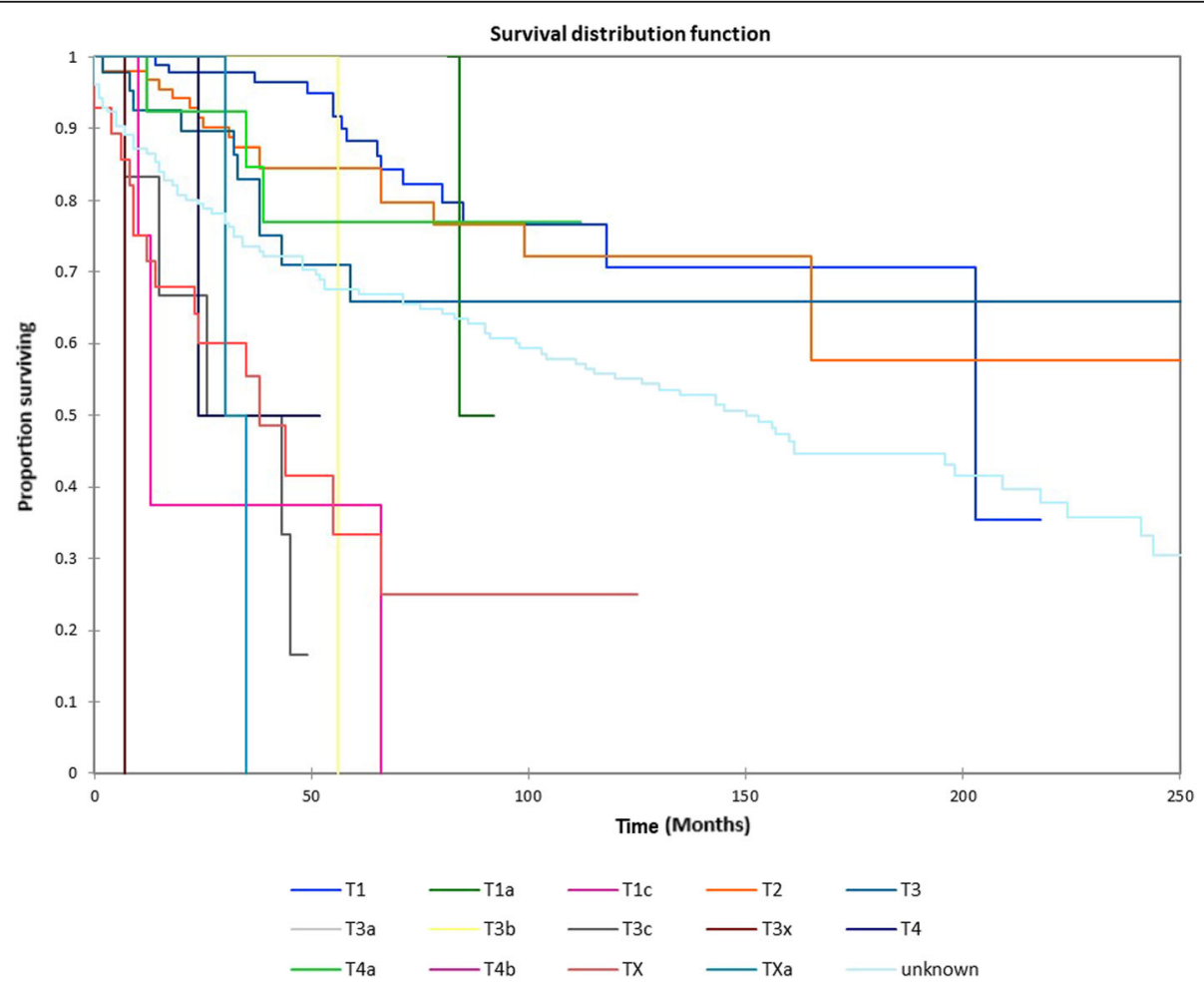

Fig. 2 Kaplan-Meier overall survival by tumor (T) stage 


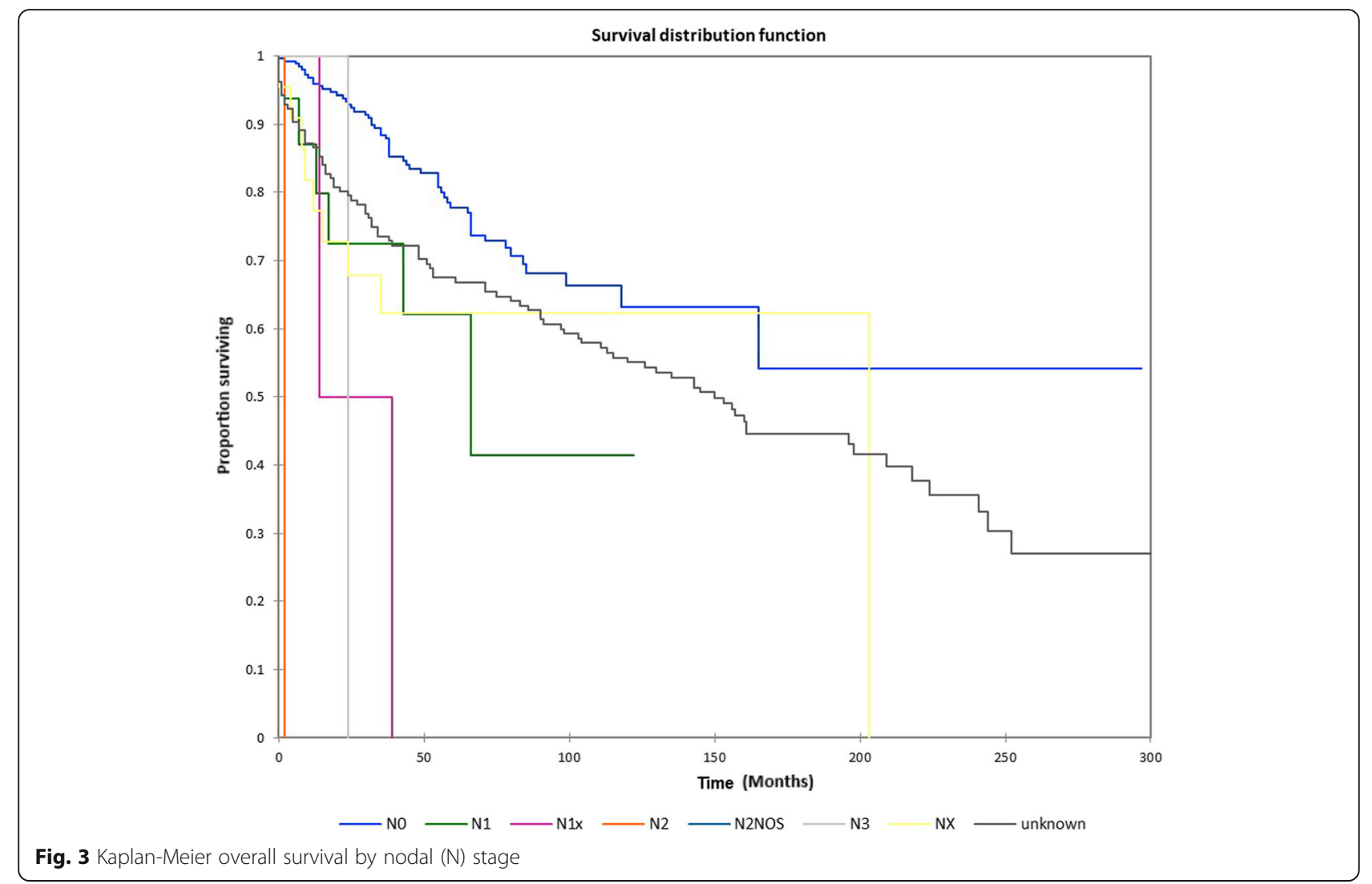

\section{Discussion}

Epithelial-myoepithelial carcinoma is an uncommon biphasic neoplasm most commonly arising in salivary tissue. It represents approximately $1 \%$ of all salivary neoplasms $[2,3]$. In their review of 246 cases of salivary gland epithelial-myoepithelial carcinoma from the 1973-2010 SEER database, Vazquez et al. [2] noted that $57.3 \%$ of patients were female. The present study noted a similar female predominance, with $62.2 \%$ of patients being female. Vazquez et al. noted a rate of distant metastases at diagnosis of $4.5 \%$. The present cohort shows an even lower M1 rate of 2.6\%. Overall disease-specific survival at 60 and 120 months in the Vazquez study was $91.3 \%$ and $90.2 \%$. The present study showed a lower overall survival of $72.7 \%$ and $59.5 \%$ at 60 and 120 months. This may be due to the inclusion in the present study of all sites including unknown primary, lung, and gastrointestinal tumors. These sites were less prevalent than salivary primary sites such as parotid and submandibular gland but had lower mean survival times, likely leading to the lower overall survival for the entire cohort. Additionally, the updated 1973-2014 data included in the present study showed a lower overall survival for parotid epithelial-myoepithelial carcinomas than submandibular and minor salivary gland tumors. In the 2015 study [2] patients with low-grade histology and lesions $<4 \mathrm{~cm}$ had significantly better survival vs. patients with high-grade histology and tumors $>4 \mathrm{~cm}$. In the present study univariate analysis showed that $\mathrm{T}$ stage, $\mathrm{N}$ stage/presence of nodal metastases, $M$ stage/presence of distant metastases, surgical treatment vs. nonsurgical treatment, overall AJCC stage, race, and age at diagnosis all significantly affected survival. Specifically, patients with T2, T3, and T4 tumors showed significantly shorter survival than patients with $\mathrm{T} 1$ tumors, patients with M1 tumors showed significantly shorter survival than M0 patients, and patients with nodal metastases showed significantly shorter survival than patients who were N0. Chen et al. [1] reported a rare case of a patient with a primary base of tongue epithelial-myoepithelial carcinoma with neck metastases and multiple lung nodules (T4N2cM1). The patient refused treatment other than biopsy and expired at 18 months post-diagnosis. In the present cohort parotid and submandibular gland were the two most common primary sites, but a statistically significant difference in survival by primary site was not found in the present study. Patients treated with surgery showed significantly increased survival relative to patients in whom surgery was not recommended, recommended but not performed for an unknown reason or in patients for whom surgery was recommended but it was unknown whether 


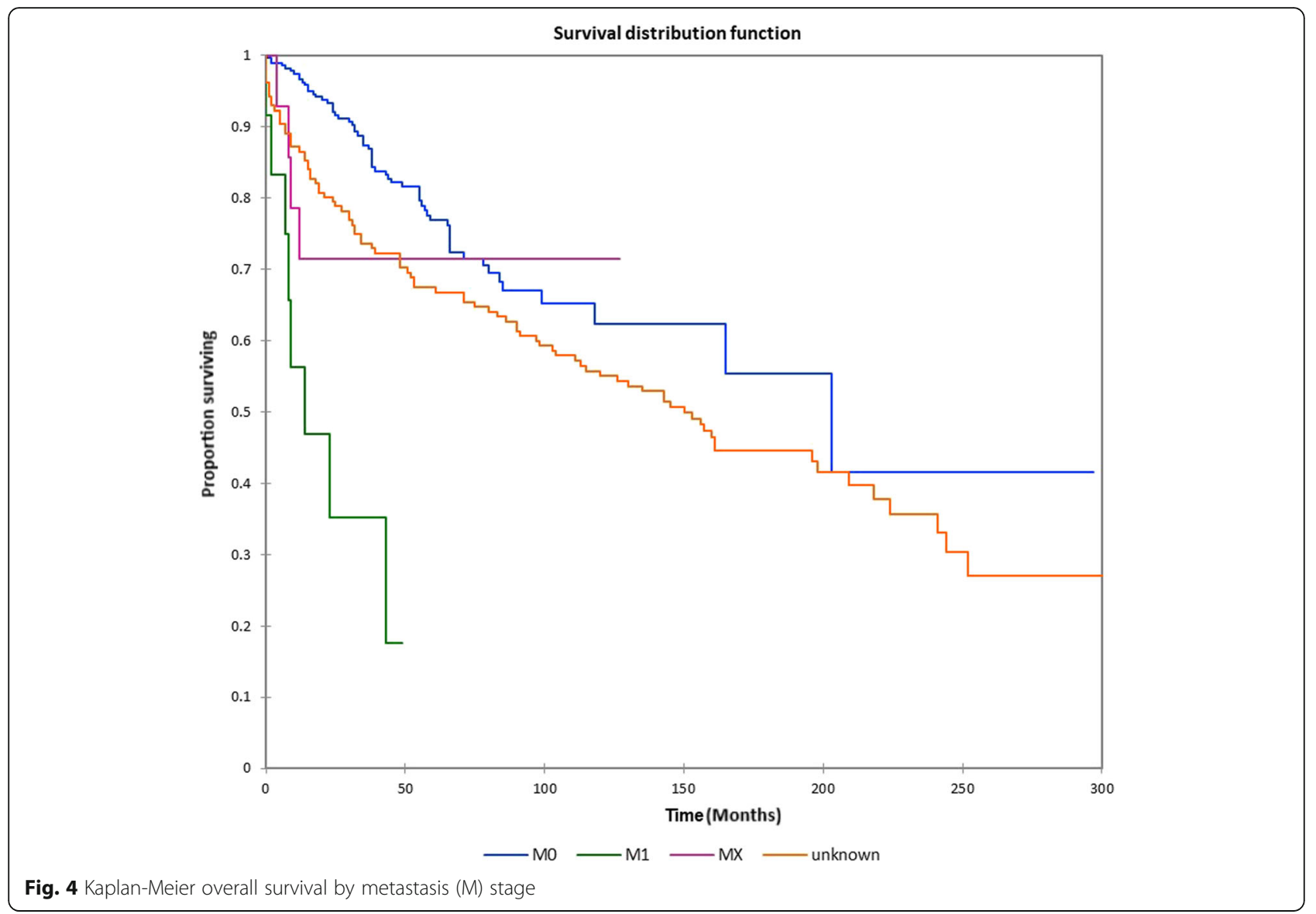

surgery was actually performed. Additionally, black patients and patients age 80 or greater at time of diagnosis had significantly shorter survival than other patients. These findings remained significant on multivariate logistic regression analysis, with overall AJCC stage, T, N, and $M$ stage, age $>80$, black race, and nonsurgical treatment significantly affecting survival.

It is interesting to note that between 1973 and 2010 there were 246 salivary gland epithelial-myoepithelial carcinomas reported (an average of approximately 6.6 per year), while in the updated data in the present study a further 70 epithelial-myoepithelial carcinomas of the major salivary glands (parotid + submandibular gland) were recorded in the next 4 years from 2010 to 2014 (an average of approximately 17.5 per year). This relative increase in numbers from 2010 to 2014 may be due to several factors. One significant factor may be Hurricane Katrina. Hurricane Katrina struck the Gulf Coast of the United States from August 23 to August 31, 2005 and significantly affected central Florida to Texas. These areas contained several major hospitals, and the SEER database specifically notes in their data set that Hurricane Katrina significantly impacted the Louisiana Cancer Registry's data reporting for the second half of
2005, and SEER excluded Louisiana cases diagnosed from July-December 2005. As this period is contained within the 1973-2010 period, this may have had some effect on the epithelial-myoepithelial carcinoma cases reported during this time period. Additionally, increased familiarity by pathologists with epithelial-myoepithelial carcinoma may have led to increased histopathological identification of this rare tumor, and decreased misdiagnosis as more common neoplasms such as mucoepidermoid carcinoma or adenoid cystic carcinoma. Finally, the increased availability and use of imaging modalities such as ultrasound, computed tomography, and magnetic resonance imaging even at smaller regional centers may have led to both increased diagnostic sensitivity for epithelial-myoepithelial carcinomas presenting as neck masses, etc., and may have also led to increased discovery of epithelial-myoepithelial carcinomas as "incidentalomas" discovered on diagnostic imaging ordered for other, unrelated reasons.

This study has several limitations. The retrospective data makes recall bias and selection bias a possibility, and the reporting limitations of the SEER database meant that a minority of the cohort had missing TNM/overall stage data. However, SEER data has been frequently used to evaluate factors affecting patient survival in rare tumors for which 


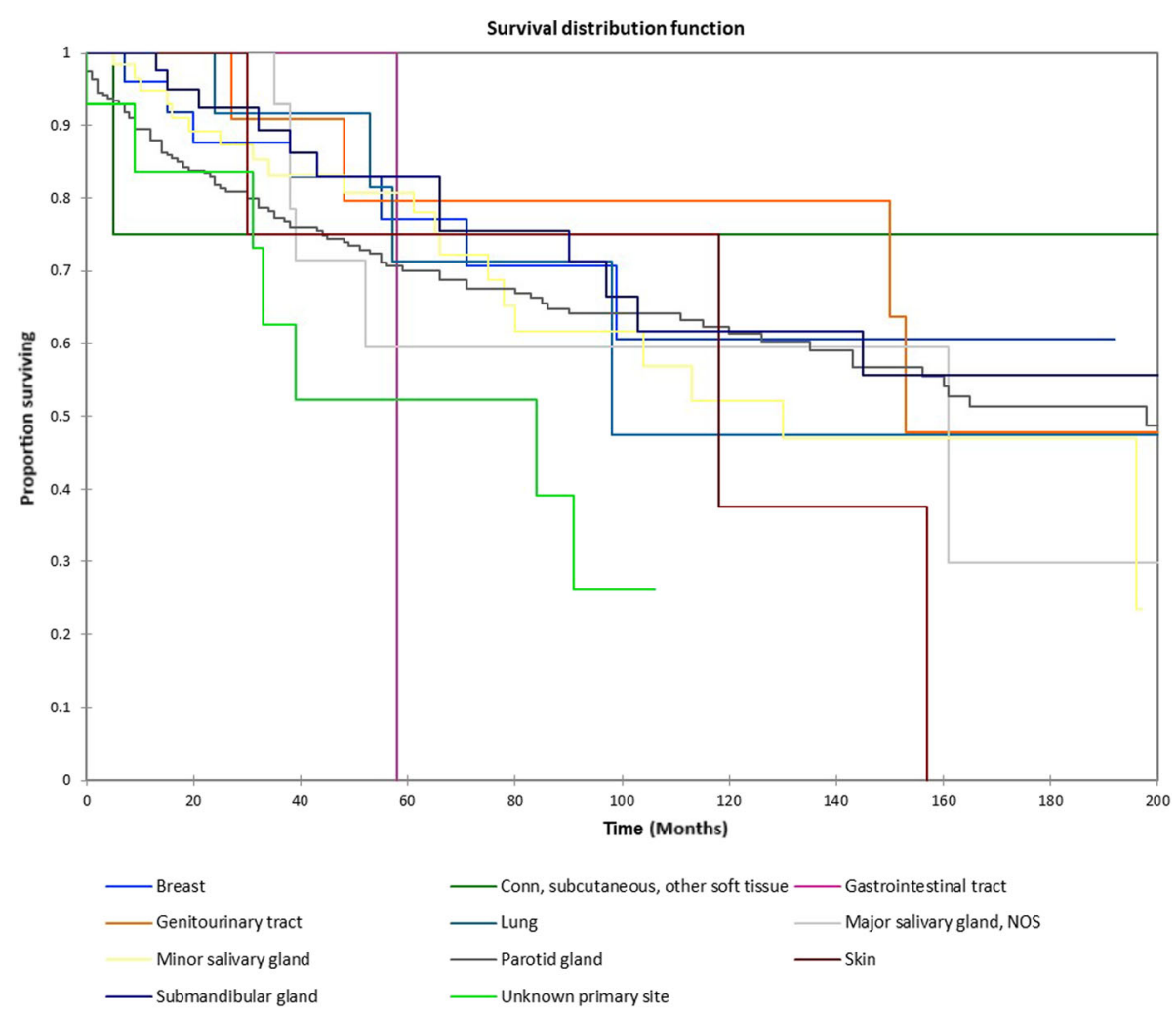

Fig. 5 Kaplan-Meier overall survival by primary site
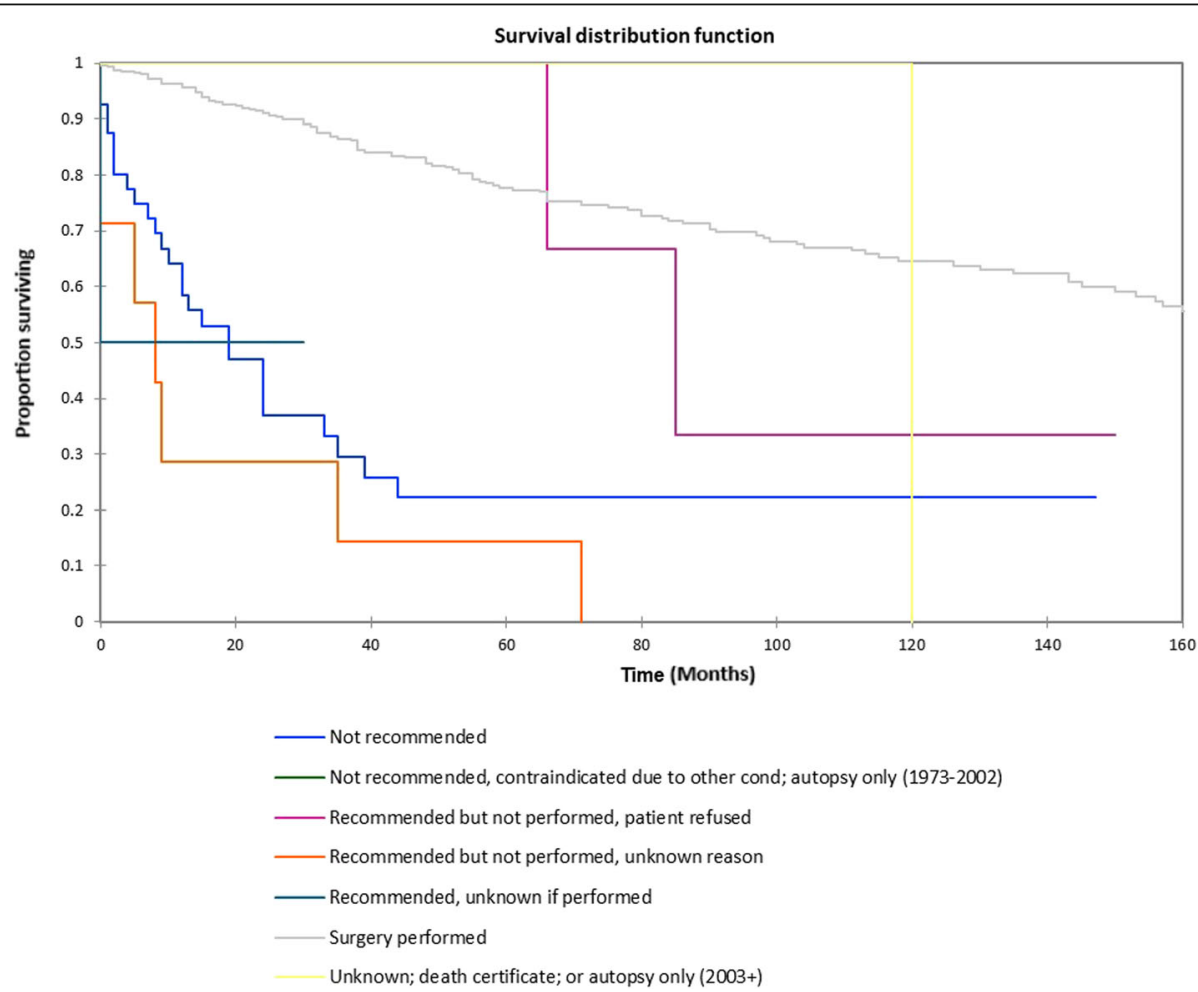

Fig. 6 Kaplan-Meier overall survival by treatment 


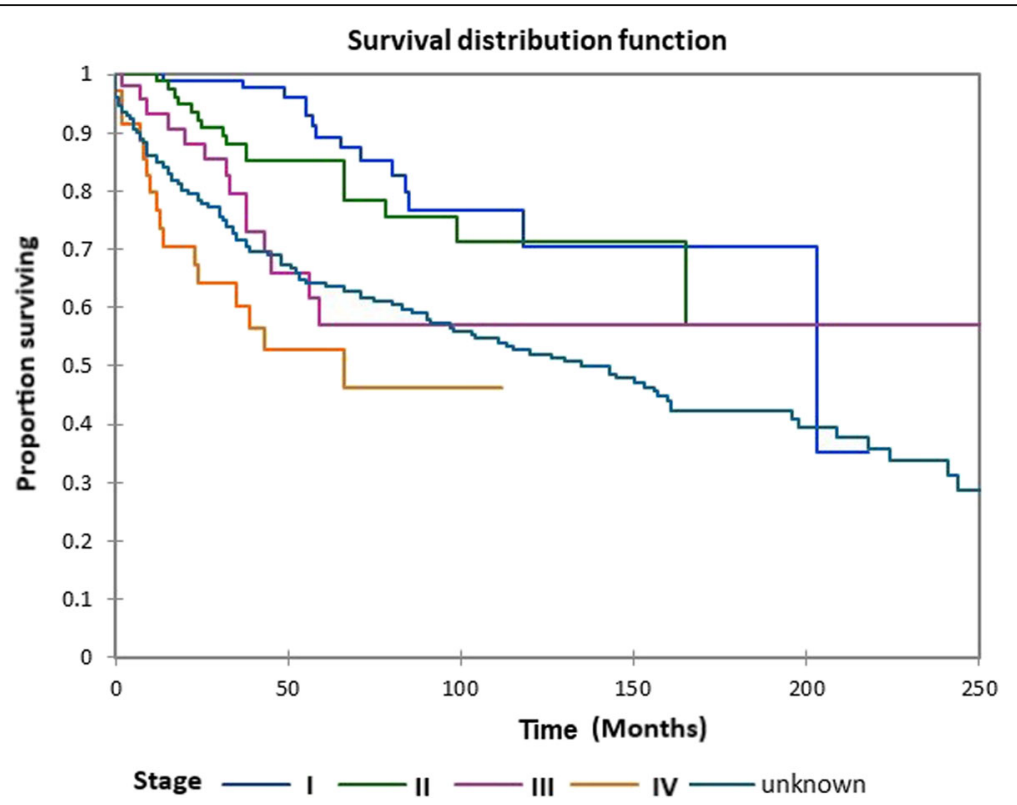

Fig. 7 Kaplan-Meier overall survival by overall AJCC (American Joint Committee on Cancer) stage

randomized prospective trials would be difficult to assemble $[2,4,5]$. The survival analysis by treatment may be confounded by co-morbidities in some patients, particularly patients in whom surgery was not recommended.

\section{Conclusions}

Epithelial-myoepithelial carcinoma is an uncommon biphasic malignancy most commonly seen in the parotid and submandibular glands. The rate of nodal and distant metastases is low; less than $5 \%$ for either in the present study. The tumor typically shows a low-to-intermediate grade behavior, with 5-, 10-, and 20-year overall survival of $72.7 \%, 59.5 \%$, and $38.3 \%$ in the present study, and a mean survival time of 165.5 months. Surgical treatment appears to be the mainstay of treatment, with radiation reserved for positive or close margins or patients who

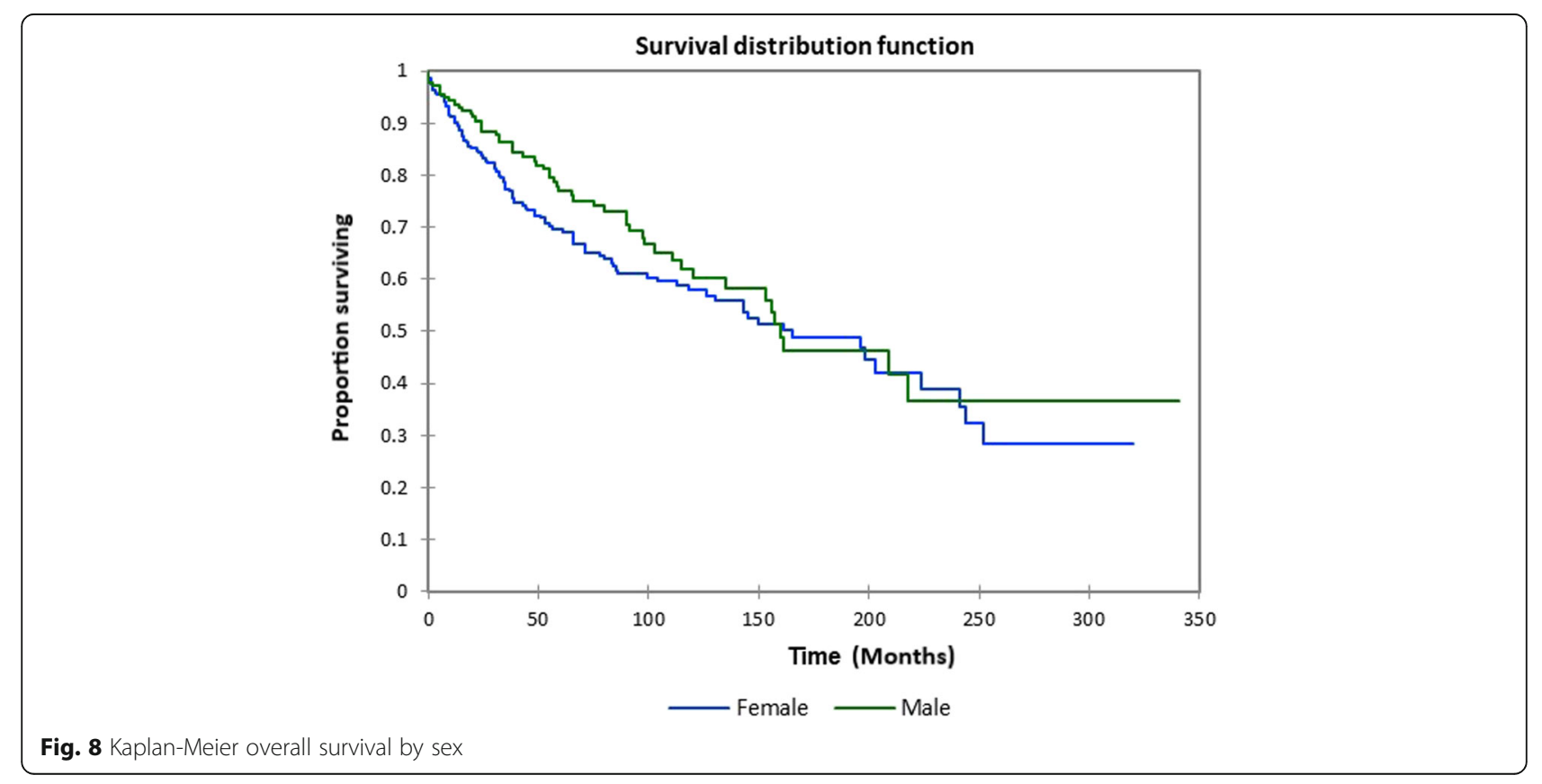




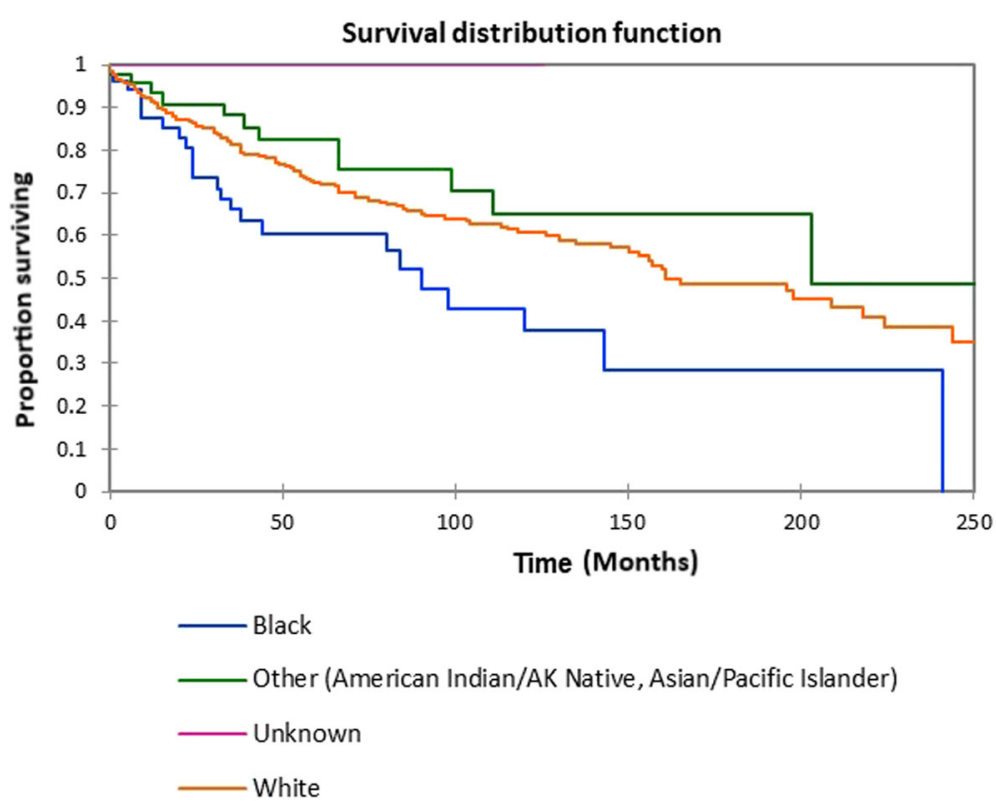

Fig. 9 Kaplan-Meier overall survival by race

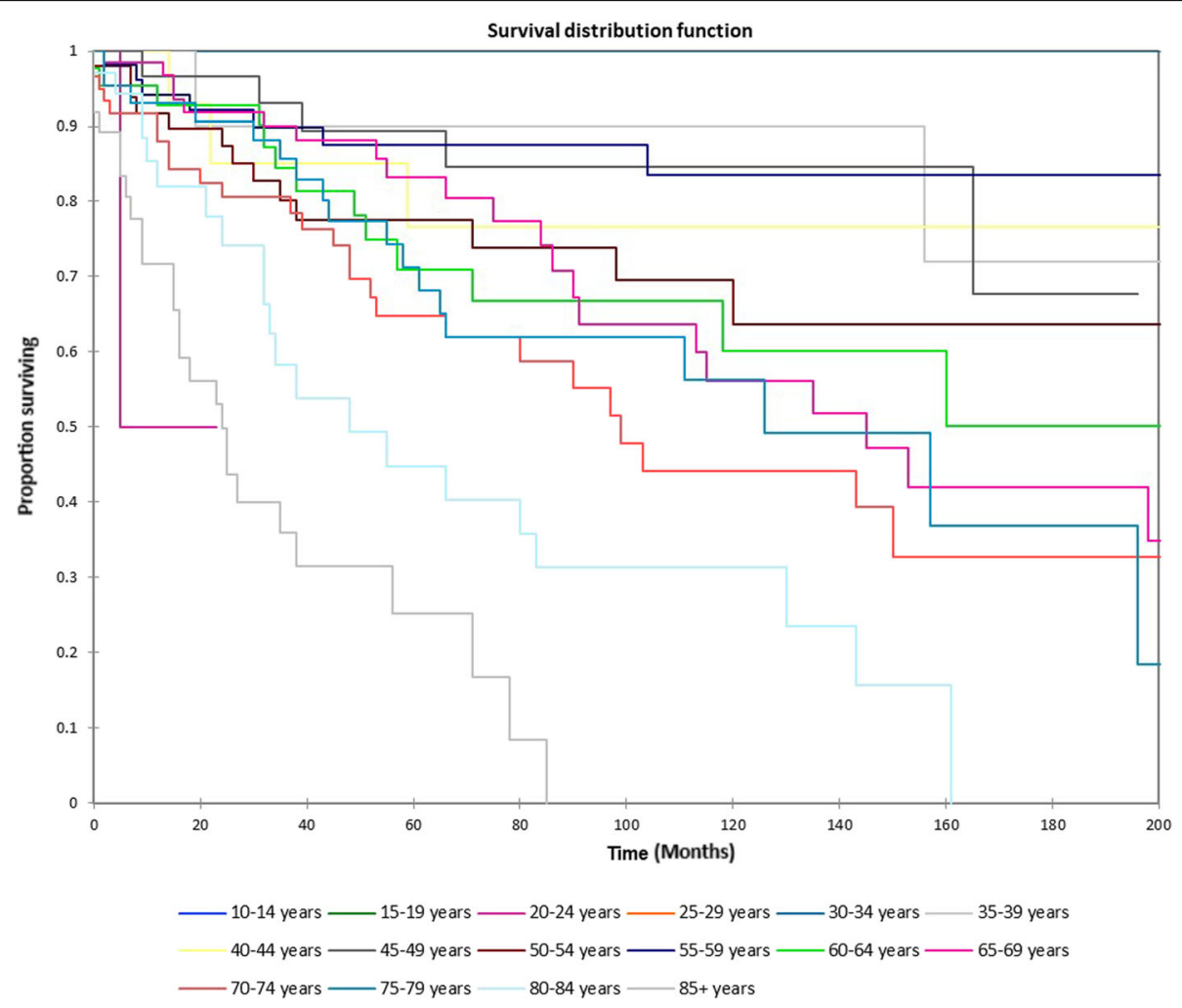

Fig. 10 Kaplan-Meier overall survival by age at diagnosis 
are not surgical candidates or who refuse surgery. Lower $\mathrm{T}$ stage, absence of regional nodal or distant metastases, age $<80$ years at diagnosis, white or Asian/pacific islander/native American race, lower overall AJCC stage, and surgical treatment all appeared to significantly affect overall survival.

\section{Abbreviations}

AJCC: American Joint Committee on Cancer; BOT: Base of tongue; M: Metastasis; N: Nodal; NOS: Not otherwise specified; OS: Overall survival;

SEER: Survival, Epidemiology, and End Results; T: Tumor

\section{Availability of data and materials}

The datasets used and analyzed during the current study are publicly available from the SEER database (https://seer.cancer.gov).

\section{Authors' contributions}

MRG conceptualized the study, wrote the manuscript, performed the SEER database query, data acquisition, data analysis, statistical analysis and

manuscript preparation, revision, editing, and approved the final manuscript.

\section{Ethics approval and consent to participate}

Not applicable.

\section{Consent for publication}

Not applicable.

\section{Competing interests}

The author declares that he/she has no competing interests.

\section{Publisher's Note}

Springer Nature remains neutral with regard to jurisdictional claims in published maps and institutional affiliations.

Received: 7 May 2018 Accepted: 13 August 2018

Published online: 16 August 2018

\section{References}

1. Chen MY, Vyas V, Sommerville R. Epithelial-myoepithelial carcinoma of the base of tongue with possible lung metastases. Case Rep Otolaryngol. 2017:2017:4973573.

2. Vázquez A, Patel TD, D'Aguillo CM, Abdou RY, Farver W, Baredes $S$, et al. Epithelial-myoepithelial carcinoma of the salivary glands: an analysis of 246 cases. Otolaryngol Head Neck Surg. 2015;153(4):569-74.

3. Peters P, Repanos C, Earnshaw J, Stark P, Burmeister B, McGuire L, et al. Epithelial-myoepithelial carcinoma of the tongue base: a case for the case-report and review of the literature. Head Neck Oncol. 2010;2:4.

4. Unsal AA, Chung SY, Unsal AB, Baredes S, Eloy JA. A population-based analysis of survival for Sinonasal rhabdomyosarcoma. Otolaryngol Head Neck Surg. 2017;157(1):142-9.

5. Chung SY, Unsal AA, Kilıç S, Baredes S, Liu JK, Eloy JA. Pediatric sinonasal malignancies: a population-based analysis. Int J Pediatr Otorhinolaryngol. 2017 Jul;98:97-102.

Ready to submit your research? Choose BMC and benefit from:
- fast, convenient online submission
- thorough peer review by experienced researchers in your field
- rapid publication on acceptance
- support for research data, including large and complex data types
- gold Open Access which fosters wider collaboration and increased citations
- maximum visibility for your research: over 100M website views per year
At BMC, research is always in progress.
Learn more biomedcentral.com/submissions

